\title{
The Effect of Postmastectomy Radiotherapy on Patients with Breast Cancer
}

Di Binnur Dönmez Yılmaz

University of Health Sciences Turkey, Prof. Dr. Cemil Taşçıoğlu City Hospital, Clinic of Radiation Oncology, İstanbul, Turkey

\section{Abstract}

Objective: Breast cancer is one of the most common types of cancer in women, and the first-line treatment for it is surgery. Depending on the patient's condition, either of the following may be selected: breast-conserving surgery, modified radical mastectomy, radical mastectomy, or simple mastectomy. According to treatment guidelines, chest wall involvement, axillary lymph involvement, and tumors $>5 \mathrm{~cm}$ should be treated with radiotherapy. Postoperative radiotherapy is required to provide local control and prevent distant metastases. In addition, chemotherapy in early stage breast cancer with axillary involvement increases survival by preventing distant metastases. The contribution of radiotherapy to local and remote control after mastectomy was examined.

Methods and Results: In this retrospective study, 1,073 breast cancer patients who were admitted to our clinic during a period of five years were included and their postoperative radiotherapy treatment results were evaluated.

Conclusion: In patients undergoing radiotherapy, a $6 \%$ local recurrence and $88 \%$ survival was found in five years. Also, locoregional recurrence was statistically and significantly lower in those undergoing radiotherapy $(\mathrm{p}=0.0001)$.

Keywords: Breast cancer, mastectomy, radiotherapy, local control, distant metastasis

\section{INTRODUCTION}

Breast cancer is one of the most common types of cancer in women and the most common cause of female death with a worldwide incidence rate of $29 \%$. A study in the United States reported that every year 46,000 out of 183,000 newly diagnosed breast cancer patients die (1). While breast cancer was detected in $17 \%$ of cancer patients who visited our outpatient clinic, the proportion of patients who underwent mastectomy was $60 \%$, which decreased over the years.

Generally, women over 50 years of age, having a relative with breast cancer, and those who give birth to their first child after 30 years of age are considered as the high-risk group (2). Breast cancer has also been associated with environmental factors in patients with similar characteristics. It is rarely seen (1\%) and has a poor prognosis in men. Tumor is localized in the upper outer quadrant in $38.5 \%$, in the upper inner quadrant in $14.2 \%$, in the central quadrant in $29 \%$, lower outer quadrant in $8.8 \%$, and lower inner quadrant in $5 \%$ of the cases. While it is frequently seen in the left breast, only $1-2 \%$ of the cases are bilateral (3).

Pathological features are important in determining the treatment and prognosis of the disease. Breast cancers are broadly classified as ductal and lobular. Ductal cancers further include carcinoma in situ, infiltrative ductal cancer, medullary cancer, tubular cancer, mucinous cancer, infiltrative lobular cancer, Paget's disease, and inflammatory breast cancer.

Moreover, for patients with operable breast cancer at early stages, radical mastectomy, modified radical mastectomy (4), simple mastectomy, and breast-conserving surgery may be used.

Radiotherapy applied accurately to the risk groups increases local control and decreases distant metastasis. In patients with 
positive axillary lymph node and skin involvement $>5 \mathrm{~cm}$, or positive surgical margin, and the tumor localized in the inner quadrant or areolar region of the breast, radiotherapy should be applied to the region of mammaria interna (5).

Interestingly, a prolonged survival has been reported with chemotherapy, particularly in patients with T1-2 and axillary involvement. While cyclophosphamide (C), methotrexate (M), and fluorouracil (F) are applied in the low-risk groups, C, adriamycin (A), and $\mathrm{F}$ are applied in the high-risk ones (6).

Additionally, tamoxifen, which is an antiestrogen, is used as an adjuvant at daily doses of $20 \mathrm{mg}$ in premenopausal and postmenopausal women (7). It also decreases the risk of breast cancer in the contralateral breast.

Although many variables are thought to affect the prognosis of breast cancer, it is based on the time from treatment to recurrence and the total survival time.

Stromal invasion: It is one of the important prognostic factors. While in situ cancers are noninvasive and treated only by mastectomy, the invasive cancers may require chemotherapy, radiotherapy, and antiestrogen therapy after surgery.

Besides, several prognostic facts have been reported to greatly impact the survival and local control, such as the number of lymph nodes involved in the axillary region, their diameter, and extracapsular invasion are used in staging. While the prognosis of patients with $<4$ axillary involvements is comparable to those without lymph node involvement, it is worse in the presence of $>4$ involvements. Thymidine-binding index determines the cells in the synthesis (S) phase of the tumor, and is considered as the basis of the decision to administer chemotherapy in patients with risk of early recurrence (8). The tumor-doubling time differs in every tumor. Large tumors generally have higher grades and frequent lymphatic invasion with worse prognosis. While the axillary lymph node involvement in tumors $<1 \mathrm{~cm}$ in size is seen in $25 \%$ of the cases, its incidence rises up to $78 \%$ in large tumors (9). Moreover, medullary, tubular, mucinous, and adenoid cystic cancers have a relatively good prognosis, however, the signet ring cell, inflammatory types, and carcinosarcomas lead a more aggressive course, and their five-year survival rate is reported to be only $11 \%(10)$. Some studies have demonstrated the association between the presence of vascular and lymphatic invasion, recurrence, and metastasis (11). Abnormal ploidy along with increased percentage of cells in $\mathrm{S}$ phase indicates lower disease-free survival and poor prognosis (12). Ki-67, showing proliferating cells in the tumor, is an indicator of early recurrence.
A majority of (70\%) breast cancer patients have estrogen receptors. The estrogen-receptor-positivity rates have been reported as $80 \%$ and $60 \%$ in patients $>60$ and $<40$ years of age, respectively (8). The presence of receptor in the tumor affects the response to hormone therapy, thereby affecting the disease prognosis. Treatment approaches in breast cancer have been standardized based on the receptor status. While in the presence of estrogen and progesterone receptors, the response rates to hormone therapy have been indicated as $55-60 \%$ and $45-60 \%$, respectively, it is reported to be only $8 \%$ in patients without estrogen or progesterone receptors (13). A $75-80 \%$ treatment response rate and improved prognosis are observed in patients having estrogen and progesterone receptors (14). Additionally, epidermal growth factor is negatively associated with estrogen-receptor positivity and is an indicator of poor prognosis (15). P-53 gene controls DNA damage and prevents the replication of damaged DNA. This feature is not present in the mutant gene. While this characteristic is not seen in $27-62 \%$ of breast cancer patients (16), C-erbB-2 is detected in $20 \%$ of the patients with breast cancer. This protein is correlated with poor histological grade and lymph node involvement (17).

\section{METHODS}

In this retrospective study, the postmastectomy treatment results of 1,073 breast cancer patients who were admitted to our clinic between 1,987 and 1,991 were evaluated. The study being retrospective, no approval from ethics committee and informed consent from the participants were required. The patients in this study had right $(n=529: 49 \%)$, left $(n=567: 51 \%)$, and bilateral breast cancers $(n=23: 2 \%)$, and the study population consisted of postmenopausal (55\%) and premenopausal patients (45\%), and $16.5 \%$ of them were $<35$ years of age.

Table 1 presents the distribution of the patients according to histological characteristics, Table 2 shows the types of surgery, and the different stages of the surgery are presented in Graphic 1.

Of note, patients who had undergone breast-conserving surgery, which make up $20 \%$ of the patients, were not included in this study.

Radiotherapy: Postmastectomy, 835 patients (77\%) underwent adjuvant radiotherapy. Of those, 50 Gy dose was delivered tangentially to the chest wall, supraclavicular, and the axillary region in 829 patients and 53-70 Gy doses to 6 patients. The remaining 238 patients (22\%) did not receive radiotherapy. 
Chemotherapy: A total of 644 patients received adjuvant chemotherapy. Most frequently, a combination of CMF, was administered to 457 patients before and after radiotherapy for a total of six courses. F-cyclophosphamide-adriamycin or epirubicin combination was added to the risky patient groups.

Surgery: Of all the patients who underwent mastectomy, axillary curettage was not performed in 354 patients and 495 of them underwent inadequate axillary dissection. In addition, there was no pathological information about axillary involvement in 86 patients (Table 3).

Hormone treatment: A total of 804 patients used tamoxifen for 1-5 years. The receptor status of the patients was not determined in premenopausal patients before hormone therapy. Tamoxifen

\begin{tabular}{|l|l|l|}
\hline Table 1. Distribution by histology \\
\hline Histological characteristics & $\mathbf{n}$ & $\%$ \\
\hline Ductal & 1009 & 0.94 \\
\hline Invasive ductal & 883 & \\
\hline Medullary & 35 & \\
\hline Scirrhous & 29 & \\
\hline Intraductal & 22 & \\
\hline Mucinous & 16 & \\
\hline Mixed & 8 & \\
\hline Comedo & 7 & \\
\hline Tubular & 6 & \\
\hline Papillary & 2 & \\
\hline Inflammatory & 1 & \\
\hline Lobular & 41 & 0.04 \\
\hline Paget's disease & 4 & 0.003 \\
\hline Others & 19 & 0.017 \\
\hline & & \\
\hline
\end{tabular}

Table 2. Types of mastectomies

\begin{tabular}{|l|l|l|}
\hline Types of surgery & $\mathbf{n}$ & $\%$ \\
\hline Simple mastectomy-axillary curettage & 538 & 49 \\
\hline Modified radical mastectomy & 395 & 36 \\
\hline Simple mastectomy & 120 & 11 \\
\hline Radical mastectomy & 43 & 4 \\
\hline
\end{tabular}

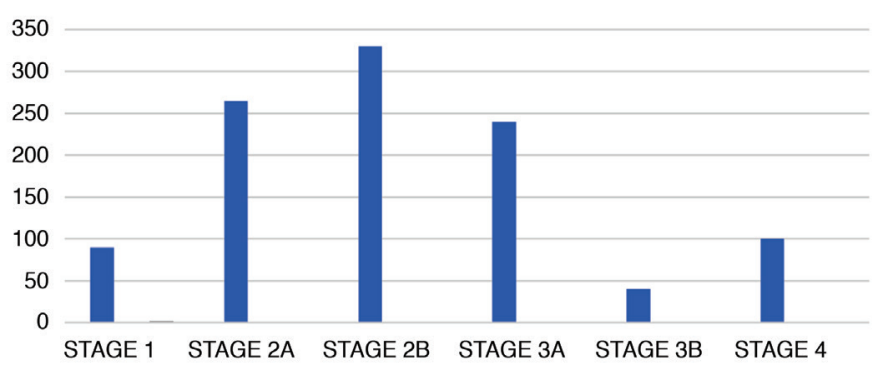

Graphic 1. Distribution by stages was administered to 92 postmenopausal and 16 premenopausal patients as an adjuvant monotherapy.

\section{RESULTS}

Local control: During the follow-up period of 84 months, local recurrence was detected in $67(6 \%)$ and regional recurrence in 19 (2\%) patients (3-60 months). Local recurrence developed in 27 (40\%) premenopausal, 39 (58\%) postmenopausal, and 1 pregnant patients. Regional recurrences, on the other hand, were detected in regions of ipsilateral axillary $(n=4)$, ipsilateral supraclavicular $(n=14)$, and mammaria interna $(n=1)$. Of the 238 patients who did not receive radiotherapy, 49 developed locoregional and 40 local recurrences. Likewise, of the 835 patients who received radiotherapy, 37 developed locoregional and 30 local recurrences. Radiotherapy reduced locoregional recurrences by 5.6 times, thereby reducing locoregional relapses both statistically and significantly ( $p=0.0001)$ (Table 4$)$. However, the difference in survival between these groups was not significant.

Distant metastases: Shortly after the onset of local recurrence, $40(60 \%)$ out of the 67 patients with local recurrences developed distant metastases. Distant metastases were seen in the bone, lung, liver, brain, and soft tissue in 185 stage $3 \mathrm{~A}$ and 94 stage 2B patients in the same order of frequency. Table 5 shows the relation between disease-free survival and survival rates and treatment outcomes.

Survival: The Cutler-Ederer method was used for the estimation of disease-free survival and survival analysis. Results were obtained after eight years of follow-up.

\begin{tabular}{|l|l|l|}
\hline \multicolumn{3}{|l|}{ Table 3. Number of dissected lymph nodes } \\
\hline Number of lymph nodes & \multicolumn{2}{l|}{ Patients } \\
\hline & $\mathbf{n}$ & $\%$ \\
\hline 0 & 354 & 27 \\
\hline $1-3$ & 306 & 18 \\
\hline $4-7$ & 189 & 30 \\
\hline $8+$ & 138 & 16 \\
\hline Unknown & 86 & 9 \\
\hline
\end{tabular}

Table 4. Effect of radiotherapy on locoregional control

\begin{tabular}{|l|l|l|l|} 
& $\begin{array}{l}\text { Without } \\
\text { radiotherapy }\end{array}$ & Radiotherapy & p value \\
\hline $\begin{array}{l}\text { Without loco/regional } \\
\text { recurrence }\end{array}$ & $79 \%$ & $95.6 \%$ & 0.0001 \\
\hline $\begin{array}{l}\text { Locoregional } \\
\text { recurrence }\end{array}$ & $20 \%$ & $4.3 \%$ & \\
\hline
\end{tabular}




\begin{tabular}{|l|l|l|l|}
\hline \multicolumn{4}{|l|}{ Table 5. Treatment modalities and results } \\
\hline & $\begin{array}{l}\text { Patients } \\
\text { number }\end{array}$ & $\begin{array}{l}\text { Disease-free } \\
\text { survival }\end{array}$ & $\begin{array}{l}\text { Survival } \\
\text { rates }\end{array}$ \\
\hline General & 1,073 & $73 \%$ & $81 \%$ \\
\hline Only RT + & 77 & $76 \%$ & $80 \%$ \\
\hline RT - & 238 & $65 \%$ & $80 \%$ \\
\hline RT + CT + TMX & 758 & $75.5 \%$ & $81 \% .5$ \\
\hline Lymph node - & 354 & $83 \%$ & $88 \%$ \\
\hline Lymph node + & 619 & $69 \%$ & $78 \%$ \\
\hline Local recurrence & 67 & $22.5 \%$ & $54 \%$ \\
\hline Distant metastasis & 406 & $22.5 \%$ & $45.5 \%$ \\
\hline RT: Radiotherapy, CT: Chemotherapy, TMX: Tamoxifen \\
\hline
\end{tabular}

\section{DISCUSSION}

Although the locoregional failure in patients undergoing surgery has been found to be at higher frequency compared to the patients who received postoperative radiotherapy, controversy about radiotherapy continues. While many studies have reported that breast cancer is a systemic disease from the beginning, and that local treatment will not be beneficial, it is important to improve the locoregional control and quality of life in a group of patients using radiotherapy.

Kae and Johansen (18) from Copenhagen compared the outcomes of radical mastectomy and radiotherapy applied after simple mastectomy in 715 patients, and after 15 years concluded that radiotherapy was more successful in preventing locoregional and distant metastases. In the first Stockholm Breast Cancer Study, the beneficial effects of pre- or postoperative radiotherapy were investigated, without any difference between both applications. However, locoregional success was reported to be better in patients undergoing radiotherapy (19). Moreover, in the combined results of the Oslo II and Stockholm Breast Cancer Studies performed to better evaluate patients who benefited from radiotherapy, it was reported that radiotherapy administration increased locoregional control and reduced distant metastases in $37 \%$ of the patients with axillary lymph node involvement (20).

On the other hand, it has been suggested that although radiotherapy may increase local control, when delivered especially to the left chest wall in cases of left breast cancer can result in cardiac deaths. Nevertheless, the rates of mortality due to cardiovascular diseases in patients undergoing postoperative radiotherapy at the Christie Hospital in England, after 14 years of follow-up, were lower than those seen in patients with local recurrence (21).
In the present study, local recurrence was observed in 21\% (49 out of 238) of the patients who did not receive postoperative radiotherapy, while it was only $4 \%$ in (out of 848 patients) those who received radiotherapy. Radiotherapy therefore reduced locoregional recurrences by 5.6 times. Besides, locoregional recurrence was also statistically and significantly lower in those undergoing radiotherapy $(p=0.0001)$. Additionally, distant metastasis developed in $60 \%$ of the patients who had local recurrences. This rate emphasizes the impact of local control on distant metastases. The survival rate of $76 \%$ in patients undergoing postoperative radiotherapy dropped to $65 \%$ when radiotherapy was not applied.

In 1995, the Early Breast Cancer Trialists' Collaborative group evaluated 17,273 patients from 36 different randomized trials and reported that postoperative radiotherapy increased local control three-fold compared to surgery but without any difference in 10-year survival rates (22). The presence and number of axillary lymph nodes involved were underlined so as to reveal the real beneficiaries from radiotherapy. Additionally, in their study, Valagussa et al. (23) demonstrated that relapses in Stage $\mathrm{T} 1$ breast cancer patients with axillary lymph node involvement were seen more frequently when compared with Stage 4 breast cancer patients without axillary involvement, and factors that are effective in locoregional success were also determined.

Further, in a radical mastectomy series followed-up for more than 50 years, Haagensen and Bodian (24) found local recurrences in $5 \%, 8-12 \%$, and $20-42 \%$ of the patients with involvement of $<4,4-7$, and $>8$ axillary lymph nodes, respectively, and recommended radiotherapy in patients with $>4$ axillary node involvement. Similarly, in the Oslo II study, it was seen that in patients with $>4$ axillary lymph node involvement and inner quadrant breast cancer, radiotherapy was more successful in increasing local control and preventing distant metastases (25). Interestingly, Fletcher et al. (26), in their study between the years 1963 and 1977, investigated 941 patients with axillary involvement and found that the 10- and 20-years survival rates were $55 \%$ and $50 \%$, respectively, in $70 \%$ of their patients who received radiotherapy. When $1-3$, and $>4$ lymph nodes were involved, the 10- and 20-year survival rates were reported as 50\% and $48 \%$, respectively. In patients with more $>4$ lymph nodes, recurrence was found most frequently in the chest wall.

When the relationship between axillary involvement and local recurrence was evaluated in our clinic, local recurrence was observed in $28 \%$ of the patients with 4-7 lymph node involvement, while it was $27 \%$ in patients without axillary 
involvement. This high rate suggests that insufficient number of axillary lymph nodes were removed and correct staging could not be performed.

Furthermore, the Danish Breast Cancer Study Group has reported that the survival rates increase as the number of investigated axillary lymph nodes increase. According to their study, a significant difference in the survival rates were seen between the patients in whom more than and less than 10 axillary lymph nodes were removed (27).

Although the increasing effectiveness of radiotherapy in patients with axillary lymph node involvement has been demonstrated, the opinion that it adversely affects survival has been entertained for years. Cuzick et al. (28) in their meta-analysis evaluated eight studies and reported that the survival was worse in patients who received radiotherapy to their chest wall and those who were followed-up for 15 years; however, the cause could not be determined.

In order to be able to demonstrate that a treatment modality is effective, there should be a risk of recurrence of the disease in that area. However, radiotherapy was applied to all operated patients without staging in the first radiotherapy studies; therefore, the contribution of radiotherapy to local control could not be demonstrated.

In 1994, Cuzick et al. (29) reported that their meta-analysis was not valid, and neither were those reported in Oslo II, Heidelberg, and I. Stockholm studies. They reported that radiotherapy could cause cardiac toxicity due to technical reasons and high energy applications. Cuzick et al. (29) also demonstrated that reducing cardiac morbidity could contribute to survival.

On the other hand, chemotherapy has become a standard postoperative application since 1970s. However, it has been shown that the success rates of chemotherapy or radiotherapy alone cannot be more than the results obtained with their combination. Sykes et al. (30) applied doxorubicin and cyclophosphamide after mastectomy to 400 stage 2-3 patients, and added radiotherapy to $38 \%$ of patients. The local recurrence rate was $15 \%$ in the group of patients who received only chemotherapy, which was twice the number of patients treated with radiotherapy.

Griem et al. (31) from the Dana Farber Institute reduced the local recurrence rate to $20 \%$ in risky breast cancer patients when only chemotherapy was applied; however, local recurrence rate dropped down to $2 \%$ when chemotherapy was combined with radiotherapy.
In the Stockholm Breast Cancer Study II (32), CMF was compared with postoperative radiotherapy, and it was demonstrated that in postmenopausal women, radiotherapy increased diseasefree survival, and at the same time decreased the rates of distant metastases in both post- and premenopausal women. Further, Fowble et al. (33) evaluated patients with 4-7 axillary lymph node involvement and tumors over $5 \mathrm{~cm}$ and reported that radiotherapy in combination with chemotherapy would contribute to local control and survival.

Although the contribution of radiotherapy to locoregional control was shown in these studies, its contribution to survival could not be demonstrated. The Danish Breast Study Group compared chemotherapy with chemotherapy plus radiotherapy in 1473 stage T3-4 risky breast cancer patients. Local control rates increased from $47 \%$ to $54 \%$ and survival rates from $63 \%$ to $68 \%$ in patients who underwent special treatment planned with the aid of tomography. The increase in survival rates was significant in patients with premenopausal patients with involvement of $>4$ axillary lymph nodes (34).

\section{CONCLUSION}

Radiotherapy delivered after mastectomy in breast cancer patients with involvement of $>4$ axillary lymph nodes and breast tumors $>5 \mathrm{~cm}$ decreases local recurrence rate from $20 \%$ to $5 \%$, and that increased local control also contributes to survival by lowering the rates of metastasis. In our patients, treatment was planned according to postoperative pathology reports, and thanks to radiotherapy applied to patients with axillary lymph node involvement, a five-year local recurrence, rate of $6 \%$, and a highly increased survival rate of $88 \%$ were achieved.

\section{Ethics}

Ethics Committee Approval: Retrospective study.

Informed Consent: The study being retrospective, no approval from informed consent from the participants were required.

Peer-review: Externally peer-reviewed.

Conflict of Interest: No conflict of interest was declared by the authors.

Financial Disclosure: The authors declared that this study received no financial support.

\section{REFERENCES}

1. Vincent T. De Vita, Rosenberg: Cancer Principles and Practice of Oncology. 1993;1264-308. 
2. Winchester DP, Bernstein JR, Paige ML. The Early Detection and Diagnosis of Breast Cancer. p1-20, Atlanta, AmericanCancerSociety; 1988.

3. Kelsey JL. A review of the epidemiology of human breast cancer. Epidemiol Rev 1979;1:74-109.

4. Topuzlu C. Meme Kanserinin Güncel Cerrahi Tedavisi. Ulusal Cerrahi Dergisi 1995;11:339.

5. Cox JD. Moss' Radiation Oncology: Rationale, techniques, results. (7th ed.) C. V. Mosby Co, St. Louis;1994.

6. Bonadonna G, Rossi A, Tancini G. Adjuvant Chemotherapy Trials in Resectable Breast Cancer with Positive Aksillary Nodes. The Experience of the Milan CancerInstitute. InJones SE, Salmon SE. Adjuvant Therapy of Cancer IX. Orlando 1984;195-207.

7. Early Breast Cancer Trialists' Collaborative Group. Effects of adjuvant tamoxifen and of cytotoxic therapy on mortality in early breast cancer. An overview of 61 randomized trials among 28,896 women. N Engl J Med 1988;319:1681-92.

8. Tavassoli FA: Pathology of the Breast.1st ed. Elsevier. 1992; 25-52.

9. Hornstein E, Skornick Y, Rozin R. The Mananagement of Breast Cancer in Pregnancy and Lactation. Journal of Surgical oncology 1978;21:179-82.

10. Donegan WL. The influence of untreated internal mammary metastases upon the course of mammary cancer. Cancer 1977;39:533-8.

11. Roses DF, Bell DA, Flotte TJ, Taylor R, Ratech H, Dubin N. Pathologic predictors of recurrence in stage 1 (TINOMO) breast cancer. Am J Clin Pathol 1982;78:817-20.

12. Ellis CN, Frey ES, Burnette JJ, Akin Jr JM, Reading C, Gaskin TA, et al The content of tumor DNA as an indicator of prognosis in patients with T1N0M0 and T2N0M0 carcinoma of the breast. Surgery 1989;106:133-8.

13. Maynard PV, Davis CJ, Blamey RW, Elston CW, Johnson J, Griffiths K. Relationship Between Estrogen Reseptor Content and Histological Grade in Human Primary Breast Tumors. Br J Cancer 1978;38:745-8.

14. Chevalier B, Heintzman F, Asselain B, Dauce JP, Bastit P, Graic Y. Prognostic Values of Estrogen and Progesteron Receptors in Operable Breast Cancer Results of a Univariate and Multivariate Analysis. Cancer 1978;62:2517-24.

15. Davis BW, Gelber R, Goldhirsch A, Hartmann WH, Hollaway L, Russell I, et al. Prognostic Significance of Peritumoral Vessel Invasion in Clinical Trials of Adjuvant Therapy for Breast Cancer with Axillary Lymph Node Metastases. Human Pathology 1985;16:1212-18.

16. Thor AD, Moore DH, Edgerton SM, Kawasaki ES, Reihsaus E, Lynch HT, et al. Accumulation of P53 Tumor Supressor Gene Protein: An Independent Marker of Prognosis in Breast Cancers. JNCI 1992;84:845-55.

17. Berger MS, Locher GW, Saurer S, Gullick WJ, Waterfield MD, Groner B, et al. Correlation of c-erb-B2 Gene Amplification and Protein Expression in Human Breast Cancer with Nodal Status and Nuclear Grading. Cancer Res 1998;48:1238-43.

18. Kae J, Johansen H. Doe Simple Mastectomy Followed by a Radiation Offer Survival Comperable to Radical Procedures? Int J Radiat Oncol Biol Phys 1977;2:1163-6.

19. Rutqvist LE, Pettersson D, Johansson H. Adjuvant radiation therapy versus surgery alone in operable breast cancer: long-term follow-up of a randomized clinical trial. Radiother Oncol 1993;26:104-10.
20. Auquier A, Rutqvist LE, Høst H, Rotstein S, Arriagada R. Post-mastectomy megavoltage radiotherapy: the Oslo and Stockholm trials. Eur J Cancer. 1992;28:433-7.

21. Jones JM, Ribeiro GG. Mortality patterns over 34 years of breast cancer patients in a clinical trial of post-operative radiotherapy. Clin Radiol 1989;40:204-8

22. Early Breast Cancer Trialists' Collaborative Group. Effects of radiotherapy and surgery in early breast cancer. An overview of the randomized trials [published correction appears in N Engl J Med 1996 Apr 11;334:1003]. N Engl J Med 1995;333:1444-55.

23. Valagussa P, Bonadonna G, Veronesi U. Patterns of relapse and survival following radical mastectomy. Analysis of 716 consecutive patients. Cancer 1978;41:1170-8.

24. Haagensen CD, Bodian C. Personal Experience with Halsted's Radical Mastectomy. Ann Surg 1992:143-50.

25. Høst $\mathrm{H}$, Brennhovt IO. The effect of post-operative radiotherapy in breast cancer. Int J Radiat OncolBiol Phys1977;2:1061-7.

26. Fletcher GH, McNeese MD, Oswald MJ. Long Range Results for Breast Cancer Patients Treated by Radical Mastectomy and Postoperative Radiotherapy without Adjuvant Radiotherapy. Int J Radiat Oncol Biol Phys 1989;17:11-4.

27. Axelsson CK, Mouridsen HT, Zedeler K. Axillary dissection of level I and II lymph nodes is important in breast cancer classification. The Danish Breast Cancer Cooperative Group (DBCG). Eur J Cancer 1992;28A:1415-8.

28. Cuzick J, Stewart H, Peto R, Baum M, Fisher B, Host H, et al. Overview of Randomised Trials of Postoperative Adjuvant Radiotherapy in Breast Cancer. Cancer Treat Rep 1987;71:15-29.

29. Cuzick J, Stewart H, Rutqvist L, Houghton J, Edwards R, Redmond C, et al. Cause-specific mortality in long-term survivors of breast cancer who participated in trials of radiotherapy. J Clin Oncol 1994;12:447-53.

30. Sykes HF, Sim DA, Wong CJ, Cassady JR, Salmon SE. Local-regional recurrence in breast cancer after mastectomy and adriamycin-based adjuvant chemotherapy: evaluation of the role of postoperative radiotherapy. Int J Radiat Oncol Biol Phys 1989;16:641-7.

31. Griem KL, Henderson IC, Gelmen R, Ascoli D, Silver B, Recht A, et al. The Five Year Results of a Randomized Trial of Adjuvant Radiation Therapy After Chemotherapy in Breast Cancer Patients Treated with Mastectomy. J Clin Oncol 1987;5:1546-55.

32. Rutqvist L, Cedermark B, Glas U, Johansson H, Rotstein S, Skoog L, et al. Randomized trial of adjuvant tamoxifen combined with postoperative radiation therapy or adjuvant chemotherapy in postmenopausal breast cancer. Cancer 1990;66:89-96

33. Fowble B, Gray R, Gilchrist K, Goodman RL, Taylor S, Tormey DC. Identification of a Subgroup of Patients with Breast Cancer and Histologically Positive Axillary Nodes Receiving Adjuvant Chemotherapy Who may Benefit fom Postoperative Radiotherapy J Clin Oncol 1988:6:1107-17.

34. Overgaard M, Christiensen JJ, Johansen H, Rasmussen AN, Rose C, van der Kooy P, et al. Evaluation of radiotherapy in high-risk breast cancer patients: report from the Danish Breast Cancer Cooperative Group (DBCG 82) Trial. Int J Radiat Oncol Biol Phys 1990;19:1121-4. 